\title{
Experimental validation of otolith-based age and growth reconstructions across multiple life stages of a critically endangered estuarine fish
}

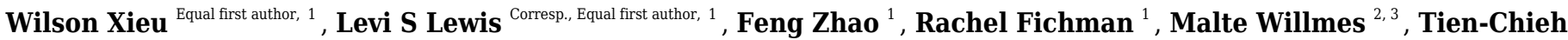 \\ Hung ${ }^{4}$, Luke Ellison ${ }^{4}$, Troy Stevenson ${ }^{4}$, Galen Tigan ${ }^{4}$, Andrew Schultz ${ }^{5}$, James Hobbs ${ }^{1,6}$ \\ 1 Department of Wildlife, Fish, and Conservation Biology, University of California, Davis, Davis, California, United States \\ Institute of Marine Sciences, University of California, Santa Cruz, Santa Cruz, California, United States \\ ${ }^{3}$ Southwest Fisheries Science Center, National Marine Fisheries Service, Santa Cruz, California, United States \\ 4 Department of Biological and Agricultural Engineering, University of California, Davis, Davis, California, United States \\ 5 Bay-Delta Office, United States Bureau of Reclamation, Sacramento, California, United States \\ 6 Bay-Delta Region, California Department of Fish and Wildlife, Stockton, CA, United States \\ Corresponding Author: Levi S Lewis \\ Email address: lewis.sci@gmail.com
}

Background. The application of otolith-based tools to inform the management and conservation of fishes first requires taxon- and stage-specific validation. The Delta Smelt (Hypomesus transpacificus), a critically endangered estuarine fish that is endemic to the upper San Francisco Estuary (SFE), California, United States, serves as a key indicator species in the SFE; thus, understanding this species' vital rates and population dynamics is valuable for assessing the overall health of the estuary. Otolith-based tools have been developed and applied across multiple life stages of Delta Smelt to reconstruct age structure, growth, phenology, and migration. However, key methodological assumptions have yet to be validated, thus limiting confidence in otolith-derived metrics that are important for informing major water management decisions in the SFE.

Methods. Using known-age cultured Delta Smelt and multiple independent otolith analysts, we examined otolith formation, otolith-somatic proportionality, aging accuracy and precision, left-right symmetry, and the effects of image magnification for larval, juvenile, and adult Delta Smelt.

Results. Overall, otolith size varied linearly with fish size (from 10-60 mm), explaining $99 \%$ of the variation in fish length, despite a unique slope for yolk-sac larvae $<10 \mathrm{~mm}$. Otolith-somatic proportionality was similar among wild and cultured specimens. Aging precision among independent analysts was $98 \%$ and aging accuracy relative to known ages was $96 \%$, with age estimates exhibiting negligible differences among left and right otoliths. Though error generally increased with age, percent error decreased from 0-30 days-post-hatch, with precision remaining relatively high ( $\geq 95 \%$ ) thereafter. Increased magnification (400x) further improved aging accuracy for the oldest, slowest-growing individuals. Together, these results indicate that otolith-based techniques provide reliable age and growth reconstructions for larval, juvenile, and adult Delta Smelt. Such experimental assessments across multiple developmental stages are key steps toward assessing confidence in otolith-derived metrics that are often used to assess the dynamics of wild fish populations. 
1 Experimental validation of otolith-based age and growth reconstructions across multiple life

2 stages of a critically endangered estuarine fish

3

4 Wilson Xieu ${ }^{1}$, Levi S. Lewis ${ }^{1 *}$, Feng Zhao ${ }^{1}$, Rachel A. Fichman ${ }^{1}$, Malte Willmes ${ }^{2,3}$, Tien-

5 Chieh Hung ${ }^{4}$, Luke Ellison ${ }^{4}$, Troy Stevenson ${ }^{4}$, Galen Tigan ${ }^{4}$, Andrew Schultz ${ }^{5}$, James Hobbs ${ }^{1,6}$

6

$7 \quad{ }^{1}$ Department of Wildlife, Fish and Conservation Biology, University of California, Davis, Davis, 8 CA, United States

$9{ }^{2}$ Institute of Marine Sciences, University of California Santa Cruz, Santa Cruz, CA, United

10 States

11 Southwest Fisheries Science Center, National Marine Fisheries Service, Santa Cruz, California, 12 United States

$13{ }^{4}$ Department of Biological and Agricultural Engineering, University of California, Davis, Byron, 14 CA, United States

$15{ }^{5}$ Bay-Delta Office, United States Bureau of Reclamation, Sacramento, CA, United States

$16{ }^{6}$ Bay-Delta Region, California Department of Fish and Wildlife, Stockton, CA, United States

$18 *$ Corresponding Author:

19 Levi S. Lewis ${ }^{1}$

201 Shields Ave., Davis, CA, 95616, United States

21 lewis.sci@gmail.com 


\section{ABSTRACT}

25

26

27

28

Background. The application of otolith-based tools to inform the management and conservation of fishes first requires taxon- and stage-specific validation. The Delta Smelt (Hypomesus transpacificus), a critically endangered estuarine fish that is endemic to the upper San Francisco Estuary (SFE), California, United States, serves as a key indicator species in the SFE; thus, understanding this species' vital rates and population dynamics is valuable for assessing the overall health of the estuary. Otolith-based tools have been developed and applied across multiple life stages of Delta Smelt to reconstruct age structure, growth, phenology, and migration. However, key methodological assumptions have yet to be validated, thus limiting confidence in otolith-derived metrics that are important for informing major water management decisions in the SFE.

Methods. Using known-age cultured Delta Smelt and multiple independent otolith analysts, we examined otolith formation, otolith-somatic proportionality, aging accuracy and precision, leftright symmetry, and the effects of image magnification for larval, juvenile, and adult Delta Smelt.

Results. Overall, otolith size varied linearly with fish size (from 10-60 mm), explaining 99\% of the variation in fish length, despite a unique slope for yolk-sac larvae $<10 \mathrm{~mm}$. Otolith-somatic proportionality was similar among wild and cultured specimens. Aging precision among independent analysts was $98 \%$ and aging accuracy relative to known ages was $96 \%$, with age estimates exhibiting negligible differences among left and right otoliths. Though error generally increased with age, percent error decreased from 0-30 days-post-hatch, with precision remaining relatively high ( $\geq 95 \%)$ thereafter. Increased magnification (400x) further improved aging accuracy for the oldest, slowest-growing individuals. Together, these results indicate that otolithbased techniques provide reliable age and growth reconstructions for larval, juvenile, and adult Delta Smelt. Such experimental assessments across multiple developmental stages are key steps toward assessing confidence in otolith-derived metrics that are often used to assess the dynamics of wild fish populations. 
54

55

56

57

58

59

60

61

62

63

64

65

66

67

68

69

70

71

72

73

74

75

76

77

78

79

80

81

82

83

84

85

86

87

88

89

90

91

92

93

94

95

\section{INTRODUCTION}

The assessment and management of fish populations require knowledge regarding their age-structure, mortality, growth, phenology, and migratory history (Maunder \& Punt, 2013). Such information is particularly valuable for endangered species, where high stakes and high uncertainty can hinder the development of effective conservation policies (Meffe, 1986; Runge, 2011). The application of schlerochronology, the study of calcareous age-registering accretionary body parts such as otoliths, vertebrae, and fin spines, in fisheries science has provided several tools to help assess the status and dynamics of managed fish populations (Hunter, Laptikhovsky \& Hollyman, 2018; Trofimova et al., 2020).

Otoliths (ear stones) are paired calcium carbonate structures found in the inner ears of bony fishes that are inert and accrete continuously throughout the life of a fish (Pannella, 1971; Campana, 1999). Otolith accretion often results in daily or annual ring patterns that can be used to quantify a fish's age while also providing a permanent archived chronology of its growth and environmental history (Pannella, 1971; Campana \& Neilson, 1985; Campana, 1999; Campana \& Thorrold, 2001; Starrs, Ebner \& Fulton, 2016). Otoliths, therefore, can be used to reconstruct the life history (Hobbs et al., 2010, 2019; Gillanders et al., 2015; Rogers et al., 2019) and vital rates (Feyrer, Sommer \& Hobbs, 2007; Black et al., 2011; Martino et al., 2019) of fishes, thus improving our understanding of their population dynamics and movement patterns (Campana, 1999; Starrs, Ebner \& Fulton, 2016; Willmes et al., 2018).

These data are critical for developing effective management plans for endangered species such as California's Delta Smelt (Hypomesus transpacificus). The Delta Smelt is an estuarine osmerid smelt that is endemic to the San Francisco Estuary, California, United States. Delta Smelt generally exhibit an annual life cycle and a complex migratory life-history (Moyle et al., 1992; Hobbs et al., 2019). Though this forage fish was historically abundant throughout the upper SFE, the population has steeply declined since the 1980 s, likely due to multiple factors including pollution, invasive species, habitat loss, hydrologic modifications, and changing environmental conditions (Feyrer, Nobriga \& Sommer, 2007; Sommer et al., 2007; Moyle et al., 2016; Hobbs et al., 2017; Moyle, Hobbs \& Durand, 2018). As a result, Delta Smelt are listed as threatened, endangered, and critically endangered under the federal Endangered Species Act (ESA), the California Endangered Species Act (CESA), and the International Union for Conservation of Nature (IUCN) Red List, respectively (U.S. Fish and Wildlife Service, 1993; CDFG, 2010; NatureServe, 2014).

The conservation status of Delta Smelt has resulted in several efforts to protect the species, including setting limits on freshwater exports that directly and indirectly impact the Delta Smelt population through entrainment and habitat modification (Grimaldo et al., 2009; Sommer et al., 2011; Miller et al., 2012; Moyle, Hobbs \& Durand, 2018; Hammock et al., 2019; Smith, Newman \& Mitchell, 2020). These restrictions on water exports have placed Delta Smelt in the crossfire between conserving species and providing a stable water supply to California's 25 million southern residents and multi-billion dollar agriculture industry (Moyle, Hobbs \& Durand, 2018). As a result, studies addressing the habitat needs and responses of Delta Smelt to natural and anthropogenic perturbations have become a key priority for managers and researchers in the region (Hobbs et al., 2017). Key elements of this include quantifying the age 
96 structure, hatch dates, movement patterns, and growth rates of Delta Smelt, all of which can

97 potentially be obtained via otolith analysis.

98 Before otoliths can be used to inform the management of fish populations, several aspects

99 of their preparation and interpretation must first be assessed experimentally including increment

100 periodicity (accuracy), inter-operator error (precision), and consistency in otolith-somatic size

101 relationships (proportionality) (Campana, 2001; Campana \& Thorrold, 2001). To accomplish

102 this, otolith validation studies are often conducted utilizing known-age cultured fish or marked-

103 recaptured wild fish (Miller \& Storck, 1982; Hoff, Logan \& Markle, 1997; Campana, 2001;

104 Roberts et al., 2004; Black, Boehlert \& Yoklavich, 2005; Hobbs et al., 2007; Sakaris \& Irwin,

105 2008; Sakaris, Buckmeier \& Smith, 2014; Buckmeier \& Howells). The application of otolith-

106 based approaches to fisheries management requires that such validations are conducted across

107 multiple developmental stages for a given species; thus, multi-stage experiments remain a key

108 step toward improving confidence and value of otolith-derived metrics.

109

110

111

112

113

114

115

116

117

118

119

120

121

122

123

124

125

126

127

128

129

130

131

132

133

134

\section{Objectives}

Otolith-based tools have been applied across multiple life stages of several imperiled osmerid smelts in the SFE (e.g., Delta Smelt and Longfin Smelt) to inform conservation and management actions. Key assumptions of these methods, however, have yet to be validated, thus limiting confidence in otolith-derived metrics that are important for informing major conservation and water management decisions in the system. Experimental validation of otolith tools for these threatened and endangered species has been identified as a critical need by state and federal resource management agencies (e.g., California Department of Fish and WildlifeCDFW and the United States Bureau of Reclamation-USBR). Here we used known-age Delta Smelt that were cultured at the UC Davis Fish Conservation and Culture Laboratory (FCCL) to examine microstructure periodicity (aging accuracy), inter-operator error (aging precision), and consistency in the otolith-somatic size relationship (proportionality). Importantly, we aimed to expand the validated age range by $300 \%$, including larvae, juveniles, and young adults, and to examine how key methodological considerations (e.g., fish age, otolith symmetry, and imaging methodology) affect accuracy and repeatability of otolith-based fisheries techniques.

Specifically, we examined otolith-somatic proportionality, left-right symmetry, initial increment formation, the accuracy, precision, and bias of age estimates, and the effects of image magnification for older, slower growing individuals. Furthermore, we contrasted otolith-somatic proportionality among cultured and wild Delta Smelt populations to assess the application of our results to the wild population. Results of this study are a valuable step toward improving confidence in past and future otolith-based age, growth, and geochemical studies which are key for informing population models and policy and management decisions.

\section{MATERIALS AND METHODS}


136

137

138

139

140

141

142

143

144

145

146

147

148

149

150

151

152

153

154

155

156

157

158

159

160

161

162

163

164

165

166

167

168

169

170

\section{1}

172

173

174

175

Laboratory-reared (F11) mature Delta Smelt were spawned, and the larvae reared in 2018-2019 at the UC Davis Fish Conservation and Culture Laboratory (FCCL) following standard methods approved by the UC Davis Institutional Animal Care and Use Committee Protocol No. 19747 (Lindberg et al., 2013). In short, fertilized eggs were incubated in columns until hatch, and all fish were held in fresh water at $16^{\circ} \mathrm{C}$. For feed, larvae $(<80 \mathrm{dph})$ receive rotifers and Artemia sp. nauplii, juveniles (80-120 dph) receive Artemia sp. Nauplii and BioOregon BioVita Starter Mash (pellet food), and older juveniles and adults ( $>120 \mathrm{dph}$ ) receive Bio-Oregon BioPro2 Crum\#1, each provided ad libitum. During culture, tanks were checked daily and fish that were either exhibiting signs of stress or collected for archival were euthanized in $500 \mathrm{mg} \mathrm{MS}-222$. Larvae were archived in 95\% ethanol at 0, 5, 10, 30, 61, and $90 \mathrm{dph}$, and adults were archived in a $-20{ }^{\circ} \mathrm{C}$ freezer at $180,215,243$, and $271 \mathrm{dph}$ ( 20 per time point). Approximately 10 archived fish were selected for each time point to examine otolith development (Table 1). Sex was not included in the analysis because all fish were less than 1 year of age and Delta Smelt do not exhibit sexual dimorphism (Wang, 2007). To contrast results with wild fish, otolith-somatic proportionality was assessed for 117 wild Delta Smelt collected and archived by the 2019 US Fish and Wildlife Service's Delta Juvenile Fish Monitoring Program (EDSM Kodiak survey, https://www.fws.gov/lodi/juvenile_fish_monitoring_program/).

\section{Length Measurements}

Adult Delta Smelt ( $\geq 180 \mathrm{dph}$ ) were imaged with a mounted Canon Powershot digital camera (Canon Solutions America Inc., Melville, New York, USA) and larvae ( $\leq 90 \mathrm{dph}$ ) were imaged at 20x magnification with an AmScope MU1000 10MP camera (AmScope, Irvine, California, USA) on a Leica StereoZoom7 dissecting microscope (Leica Camera Inc., Allendale, New Jersey, USA). All images included millimeter markers to facilitate image calibration and measurements. Digital measurements of standard length (SL), fork length (FL), and total length (TL) (Fig. 1A) were collected for each fish using ImageJ (version 1.8.0) (Abramoff, Magelhaes $\&$ Ram, 2006). Digital and hand measurements of standard length yielded nearly identical measurements (mean difference $=0.57 \mathrm{~mm}$ or $1.08 \%$ ) (Fig. S1), thus were treated interchangeably as needed. To correct for preservation effects (Fowler \& Smith, 1983; Fey, 1999), fresh "corrected" standard lengths $\left(\mathrm{SL}_{\mathrm{c}}\right)$ were calculated using empirical linear models developed in the laboratory for specimens that were measured fresh $\left(\mathrm{SL}_{\mathrm{f}}\right.$ or $\left.\mathrm{TL}_{\mathrm{f}}\right)$ and then preserved in $95 \%$ ethanol $\left(\mathrm{SL}_{\mathrm{e}}\right.$, slope $=1.018$, intercept $\left.=0.952, \mathrm{R}^{2}=0.977, \mathrm{n}=35\right)$ or were frozen at $-20^{\circ} \mathrm{C}\left(\mathrm{SL}_{\mathrm{z}}\right.$, slope $=1.018$, intercept $\left.=1.524, \mathrm{R}^{2}=0.980, \mathrm{n}=36\right)($ Fig. S1 $)$. The smallest larvae in the otolith study, however, were beyond the size range used to develop the ethanol conversion function, resulting in over-estimation of larval fish sizes. Therefore, the mean proportional difference was applied in lieu of linear correction functions (Fig. S1).

\section{Otolith Preparation}

Sagittal otoliths from larval, juvenile, and adult Delta Smelt (Fig. 1A) were dissected and mounted using standard methods, adapted for the size of each age class (Hobbs et al., 2007, 2019). Otoliths from larvae were dissected using 30-gauge hypodermic needles and mounted on top of a drop of Loctite Super Glue and imaged with a drop of glycerin at 1000x magnification.

Peer] reviewing PDF | (2021:01:56842:2:0:NEW 10 Sep 2021) 
176 Adults and juveniles were dissected using size 10 scalpel blades and ultra-fine tip forceps. Prior

177 to sanding and polishing, whole, intact otoliths of fish $\geq 180 \mathrm{dph}$ were imaged at 40x

178 magnification, while those of fish between 30-90 dph were imaged at 200x magnification. All

179 whole otolith images were taken with an Amscope MU1000 10-Megapixel camera on an

180 Olympus CH30 compound microscope. The rostrum-postrostrum and dorsal-ventral

181 measurements were digitally measured using ImageJ (version 1.8.0). After imaging, otoliths

182 were mounted in the sagittal plane to glass microscope slides using Crystal Bond thermoplastic

183 glue and stored in plastic microscope slide boxes.

184 Mounted otoliths were wet sanded with 600, 800, and 1200 grit Buehler MicroCut silicon

185 carbide paper and polished with 0.3- $\mu \mathrm{m}$ Buehler MicroPolish alumina on a Buehler Microcloth

186 (Buehler, Lake Bluff, Illinois, USA) on the sulcus side, then flipped and sanded to expose the

187 core (the section of the otolith around the primordium, the origin of otolith material deposition,

188 that is bound by the hatch mark) and daily increments. All polished otoliths were imaged at

189 200x, with additional images captured at 400x magnification for $271 \mathrm{dph}$ fish (Table 1). All

190 images were taken using an Amscope MU1000 10MP camera on an Olympus CH30 compound

191 microscope and stitched together using the photo merge function in Adobe Photoshop 2020 (v.

192 21.1.1). Left otoliths were initially sanded; however, if the left otolith was broken, lost, or of

193 poor quality, the right otolith was prepared in its place. For the comparison of otolith symmetry,

194 a subset of fish had both the left and right otoliths prepared: $90 \mathrm{dph}(\mathrm{n}=5)$ and $180 \mathrm{dph}(\mathrm{n}=5)$ age

195 groups (Table 1). In total, 108 Delta Smelt (120 otoliths) were examined achieving

196 approximately 10 samples in each age class (Table 1) for individuals aged 0-271 dph and 5.41 to

$19757.38 \mathrm{~mm}$ SL (Table 1).

\section{Otolith Age and Growth Analyses}

199

200

201

202

203

204

205

206

207

208

209

210

211

212

213

214

215

The quality of each otolith image was ranked on a scale of 0 to 3 (low to high, respectively) based on the clarity of the core and edge increments, with only quality 2 and 3 otoliths used in analyses. All otoliths were analyzed with ImageJ by three independent analysts without prior knowledge of each fish's age. Images were calibrated from pixels to $\mu \mathrm{m}$ using a stage micrometer. Increments were counted from the core to the dorsal edge, excluding embryonic rings present within the core, which provided the most consistent and clear age trajectory on the otolith (Hobbs et al., 2007) (Fig. 1B). A distinct hatch mark, indicating the moment larvae emerge from eggs into the ambient environment, was observable in each otolith as a thick, dark band approximately $8 \mu \mathrm{m}$ from the primordium. This was used to identify the first daily increment from which the growth profile was constructed for each otolith (Fig. 1C, "core").

\section{Accuracy}

Accuracy was quantified to assess how well otolith-based age estimates reflect the known ages of cultured Delta Smelt. Error in accuracy $\left(E A_{f i}\right)$ of a given age estimate for a given fish, reflecting both accuracy and bias (in days), was calculated as the raw deviation from the known age of the fish:

PeerJ reviewing PDF | (2021:01:56842:2:0:NEW 10 Sep 2021) 
216 Equation 1: $E A_{f i}=a_{f i}-\hat{a_{f}}$

217

218

219

220

221

222

223

224

225

226

227

228

229

230

231

232

233

234

235

236

237

238

239

240

241

242

243

244

245

246

247

248

249

250

251

252

where $a_{f i}$ is the $i$ th age estimate and $\widehat{a_{f}}$ is the known age of the $f$ th fish. Percent error in accuracy $\left(\mathrm{PEA}_{f i}\right)$ of a given age estimate, an age-normalized estimate of the absolute error, was calculated as 100 times the ratio of the absolute error and the known age of the $f$ th fish.

Equation 2: $P E A_{f i}=\frac{\left|E A_{f i}\right|}{\hat{a_{f}}} * 100$

\section{Precision}

Precision was quantified to assess the reproducibility of repeated age estimates among the three independent analysts (Campana, 2001). Error in precision $\left(E P_{f i}\right)$ of a given age estimate for a given fish was calculated as the raw deviation (in days) from the mean age estimate of the fish:

Equation 4: $E P_{f i}=a_{f i}-\overline{a_{f}}$

where $\overline{a_{f}}$ is the mean age estimate for the $f$ th fish. Percent error in precision $\left(P E P_{f i}\right)$ for a given fish, an age-normalized estimate of the absolute inter-operator error, was calculated as 100 times the ratio of the absolute precision error and mean age estimate of a given fish:

Equation 5: $P E P_{f i}=\frac{\left|E P_{f}\right|}{\overline{a_{f}}} * 100$

\section{Statistical Analyses}

First, to describe the general somatic growth curve for cultured Delta Smelt, size-at-age was modeled using a Gompertz growth function with the known ages ( $t=$ time in days-posthatch, dph) of cultured fish and their standard lengths $\left(\mathrm{SL}_{\mathrm{c}}\right)$ where $k_{g}$ is the growth rate coefficient, $A$ is the upper asymptote, and $c$ is related to the time at inflection (Tjørve \& Tjørve, 2017) (Eqn. 6).

Equation 6: $S L_{c} \sim A * e^{-\mathrm{c} * e^{-k} g^{* \mathrm{t}}}$

Fish size was then contrasted with otolith size using simple linear regression to assess otolith-size to fish-size (OS-FS) proportionality, and OS-FS proportionality was contrasted among cultured and wild adult Delta Smelt using a linear model. To examine the additive and interactive contributions of analyst identity, otolith side, and fish age on the accuracy (PEA) of otolith-based age estimates, a subset of larval (90 dph, $\mathrm{n}=5)$ and adult (180 dph, $\mathrm{n}=5$ ) Delta Smelt were selected to have both the left and right otoliths analyzed. Both otoliths from each fish were aged by each of the three analysts, and a linear model was constructed to examine the additive and interactive effects of analyst identity $(I)$, otolith side $(O)$, and age class $(A)$ on the accuracy (PEA) of age estimates (Eqn. 7). 
253

254

255

256

257

258

259

260

261

262

263

264

265

266

267

268

269

270

271

272

273

274

275

276

277

278

279

280

281

282

283

284

285

286

287

288

289

290

291

292

293

Equation 7: $P E A=\beta_{0}+\beta_{1} I+\beta_{2} O+\beta_{3} A+\beta_{4} I O+\beta_{5} I A+\beta_{6} O A+\beta_{7} I O A+\varepsilon$

$\varepsilon \sim N\left(0, \sigma^{2}\right)$

To examine the interactive effects of microscope magnification and analyst identity on the accuracy (PEA) of otolith-based age estimates for the oldest, slowest growing individuals (with the smallest rings), one otolith for each of the age-271 dph Delta Smelt (N=9) was imaged at both 200x and 400x magnification, with both images being aged by each of the three analysts, and a linear model was constructed to examine the additive and interactive effects of analyst identity $(I)$ and image magnification $(M)$ on the accuracy $(P E A)$ of age estimates (Eqn. 8).

Equation 8: $P E A=\beta_{0}+\beta_{1} I+\beta_{2} M+\beta_{3} I M+\varepsilon$

$\varepsilon \sim N\left(0, \sigma^{2}\right)$

All ordination and modeling were conducted in the R software environment version 3.6.3 (R Core Team, 2020). The Gompertz model was fit using the "nls" function, which determines the nonlinear (weighted) least-squares estimates of the parameters of a nonlinear model. Models were run and compared using maximum likelihood estimation while assuming a Gaussian distribution. Model assumptions were examined using Q-Q and residual plots. Likelihood ratio tests were used to assess the significance of each model relative to the null model (intercept only) with $\alpha=0.05$.

\section{RESULTS}

\section{Somatic and Otolith Growth}

The Gompertz growth model provided a reasonable fit to size-at-age of cultured Delta Smelt $\left(\mathrm{A}=62.15, \mathrm{c}=2.20, \mathrm{k}_{\mathrm{g}}=0.012, \mathrm{R}^{2}=0.994\right)($ Fig. $2 \mathrm{~A})$. Overall, otolith size varied strongly and linearly with fish size (slope $=0.070 \pm 0.001$, intercept $=6.79, \mathrm{R}^{2}=0.988$ ), indicating that otolith growth is largely proportional to fish growth across the age classes examined (Fig. 2B). The smallest larvae, however, exhibited an inflection at approximately 10 $\mathrm{mm}$ SL (otolith radius $=18.96 \mu \mathrm{m})$, with newly-hatched yolk-sac larvae $<10 \mathrm{~mm}(\sim 10 \mathrm{dph})$ exhibiting a steeper slope of $0.282 \pm 0.03$, and all older individuals exhibiting a constant slope of $0.069 \pm 0.001$, similar to the global slope of 0.070 (Fig. S2, Table S1). Mean \pm s.d. otolithsomatic ratios of juvenile-adult $(>35 \mathrm{~mm})$ cultured and wild Delta Smelt were $12.0 \pm 0.8$ and $12.27 \pm 1.0 \mu \mathrm{m} / \mathrm{mm}$, respectively, and did not differ significantly between the two groups $(\mathrm{t}=$ $1.82, \mathrm{df}=97.3, \mathrm{p}=0.072$, Fig $2 \mathrm{~B})$. Otoliths exhibited a single primordium with core sizes (otolith radius at hatch) of $8.5 \pm 1.5 \mu \mathrm{m}$ (mean \pm s.d.) (Fig. $2 \mathrm{C}$ ), corresponding with a size-athatch of $5.41 \pm 0.17 \mathrm{~mm}$ (mean \pm s.d.) standard length. Otolith growth profiles exhibited ontogenetic variation in accretion rates, with slower rates of $1-2 \mu \mathrm{m} / \mathrm{d}$ for fish $<30 \mathrm{dph}$, increasing to over $8 \mu \mathrm{m} / \mathrm{d}$ in $50-100 \mathrm{dph}$ fish, followed again by a gradual decrease back to 2 $\mu \mathrm{m} / \mathrm{d}$ as fish matured toward $270 \mathrm{dph}$ (Fig. 2D).

Peer] reviewing PDF | (2021:01:56842:2:0:NEW 10 Sep 2021) 
294

295

296

297

298

299

300

301

302

303

304

305

306

307

308

309

310

311

312

313

314

315

316

317

318

319

320

321

322

323

324

325

326

327

328

329

330

331

332

Error in accuracy changed from 0 to 10 days as known ages increased from 5 to $271 \mathrm{dph}$, indicating negative bias in older specimens (Fig. 3A). Absolute percent error in accuracy declined from $20 \%$ to $2 \%$ in fishes of age 5-90 dph, increasing to 3-4\% in older $243-271 \mathrm{dph}$ fish (Fig. 3B). Due to the sensitivity of percent error to small deviations in fish $<10 \mathrm{dph}$, mean error and percent error in accuracy and precision were only contrasted for fish $\geq 10 \mathrm{dph}$. Mean EA and PEA across all age classes (10-271 dph) and the three analysts were -3.6 days and 3.9\%, respectively, and values for each were similar among analysts (Fig. 4A-B). Mean percent error in precision across all age classes and analysts was $2.2 \%$ (Fig. $4 \mathrm{c}$ ), and also was similar among analysts. These errors correspond with relatively high accuracy (96.1\%) and precision (97.8\%), thus confirming the proper identification of the hatch mark and first increment, daily periodicity of increment formation, and both accurate and repeatable age estimation by multiple independent analysts.

Effects of Otolith Symmetry, Image Magnification, and Life Stage on Aging Accuracy Among Analysts

The 90-dph and 180-dph fish, for which both otoliths were analyzed, exhibited mean absolute percent error in accuracy (PEA) of 1-2\%, which did not appear to vary as additive or interactive functions of life stage, otolith side, or analyst (Table 2, Fig. 5). For the oldest fishes examined (271 dph), however, error was often biased 7-10 days lower than the known age (Fig. 4A), suggesting that the smaller increments in these slower-growing specimens were often inconspicuous and overlooked. Re-imaging of older specimens at higher magnification (400x versus 200x) yielded significant improvement in age estimates for older fish, reducing mean bias to $0.25 \%$ (Table 3, Fig. 5).

\section{DISCUSSION}

\section{Experimental validation of otolith-based metrics}

Validation studies are essential for assessing confidence in otolith-derived metrics (Campana, 1990, 2001). Our results build upon prior work to refine and expand our understanding of the accuracy and precision of otolith-based tools for a critically endangered estuarine fish. Using cultured, known-age specimens and multiple independent analysts, we demonstrated daily periodicity of increment formation and high accuracy and precision of age estimates. The limited asymmetry observed between left and right otoliths suggested that either otolith can likely be utilized, and increased magnification improved aging precision, indicating that otolith approaches can be applied to older fish with slower accretion rates. In aggregate, our results indicate that the application of otolith-based techniques to archived collections of Delta Smelt can yield repeatable, accurate, and valuable estimates of the hatch dates, age structure, growth rates, and timing of movements (when paired with otolith chemistry) across life stages (Hobbs et al., 2007, 2019). Such experimental approaches using multiple independent analysts 
333

334

335

336

337

338

339

340

341

342

343

344

345

346

347

348

349

350

351

352

353

354

355

356

357

358

359

360

361

362

363

364

365

366

367

368

369

370

371

372

and known-age specimens across key developmental stages can greatly improve confidence in otolith-derived metrics that are valuable for informing resource management and species conservation.

\section{Interpretation of Otolith Microstructures}

For many fish species, the first otolith increment is visible following a dark, thick "hatch check" which is assumed to form when larvae emerge from eggs into the ambient environment (Campana \& Neilson, 1985; Ohama, 1990). However, verification of the timing of such features is necessary to facilitate accurate age reconstructions for each species. For example, features identified as hatch checks may correspond with other processes, such as the end of the yolk-sac stage or first-feeding (Moksness, 1992; Sepulveda, 1994; Hirose \& Kawaguchi, 2001), and embryonic rings can form prior to hatch and with unknown periodicity (Stevenson \& Campana, 1992). In Delta Smelt otoliths, a distinct hatch check was consistently observed at approximately $8-9 \mu \mathrm{m}$ from the center of the otolith primordium. We also observed embryonic rings of unknown periodicity that are generally excluded from increment analyses (Stevenson \& Campana, 1992). Following the hatch check, increments were accreted daily as evidenced by strong agreement between increment counts and known ages of each fish. Though the first observations of Delta Smelt otoliths suggested that increments first formed at 5 dph (Hobbs et al., 2007), we believe this was likely due to the lower resolution (e.g., 1 megapixel) digital cameras available at that time, with lower image quality obscuring the smallest larval increments. Thus, Delta Smelt exhibit clear microstructures including a single primordium, a prominent hatch check, and daily increments that, together, facilitate accurate reconstructions of hatch dates and size-at-age.

\section{Otolith-Somatic Proportionality}

A simple linear model indicated that $99 \%$ of the variation in fish size (SL) could be explained by otolith size across the range of age classes examined (0-271 dph). This result indicated that, for Delta Smelt, otolith-somatic proportionality is largely constant - a key assumption of standard models used to estimate size and growth rates from otolith radii and accretion rates, respectively (Campana, 1990). Furthermore, otolith-somatic ratios differed by $<$ $3 \%$ between cultured and wild fish, suggesting that otolith-based tools likely can be applied to the wild population (Fig. 2B). Closer inspection of otolith-somatic proportionality immediately after hatch (e.g., fish $<10 \mathrm{~mm}$ or $10 \mathrm{dph}$ ), indicated that prolarvae may exhibit rapid somatic growth immediately after hatching despite low rates of otolith accretion; a phenomenon also observed in early otolith work on Delta Smelt larvae (Hobbs et al., 2007). During this early larval period, elongation (growth) was proportional to otolith growth, but exhibited a higher slope than the value observed in larger $(>10 \mathrm{~mm}$ ) fish (Fig. S2). This early larval stage is heavily reliant on endogenous sources of nutrition such as the yolk and oil globule (Mager et al., 2004). At approximately $10 \mathrm{dph}$, when endogenous reserves are exhausted and larvae become dependent on exogenous feeding (Mager et al., 2004), the somatic-otolith relationship decreased abruptly and remained constant thereafter for all age classes (i.e., 10-271 dph). This short-lived discontinuity in slopes had little influence on the overall somatic-otolith relationship $(\mathrm{m}=0.069$ 
373

374

375

376

377

378

379

380

381

382

383

384

385

386

387

388

389

390

391

392

393

394

395

396

397

398

399

400

401

402

403

404

405

406

407

408

409

410

411

412

vs 0.072 , Fig. S2) for estimating the growth of older life stages, but would be important for otolith-based growth and size estimates for the youngest larvae (Fig. S2). In sum, otoliths of Delta Smelt exhibited constant proportionality for all exogenously feeding life stages (10-271 dph), with results similar among cultured and wild fish, thus further verifying their value for estimating somatic growth rates (Campana, 2001; Hobbs et al., 2007).

\section{Accuracy and Precision of Otolith-based Age Estimates}

Validation experiments can be relatively challenging for sensitive, critically endangered species such as Delta Smelt. Here, we leveraged on-going efforts by the UC Davis Fish Conservation and Culture Laboratory to maintain a captive population of Delta Smelt for both conservation and research purposes, which provided a unique opportunity to build an archive of otoliths from known-age individuals across multiple age classes. Such an archive is uniquely valuable for assessing the accuracy and repeatability of otolith-based size, age, and schlerochronological reconstructions. Using known-age cultured fish and multiple independent analysts, we demonstrated relatively high $(>95 \%)$ accuracy and precision of otolith-based age estimates for Delta Smelt.

Obtaining acceptable levels of accuracy and precision in age estimates from otoliths requires finely calibrated otolith preparation and imaging protocols, and subsequent training of analysts, to facilitate clear and accurate interpretations of daily increments. With careful preparation, daily increments can be observed in otoliths of Delta Smelt as fine rings (microstructures) that exhibit a consistent and readily-interpretable appearance, as observed in many fishes (Stevenson \& Campana, 1992). Poor preparation, however, can result in multi-day check marks or smaller sub-daily rings that generate systematic bias in age and growth reconstructions (Campana \& Neilson, 1985; Stevenson \& Campana, 1992). For example, undersanding can result in thick samples that emphasize larger multi-day checks that obscure the true daily increments, while over-sanding can result in extra thin samples that emphasize sub-daily otolith features or image artifacts that occur at a higher frequency than the true daily increments. For these reasons, archives of known-age specimens are needed, proper quality assurance and control (QAQC) procedures should be employed, and only high-quality preparations and welltrained analysts should be used in otolith-based studies of wild populations, where precision is assessed while accuracy is assumed (Campana, 1990; Hobbs et al., 2019).

\section{Otolith Symmetry}

Paired otoliths in fishes may exhibit varying degrees of asymmetry (Lychakov et al., 2006, 2008; Díaz-Gil et al., 2015). Symmetrical otoliths can be valuable for studying rare species, where each specimen is highly valuable. For example, to control for potential effects of asymmetry (Mahé et al., 2019), otolith protocols often use only left or right otoliths, replacing entire specimens if the selected otolith is lost, damaged, or otherwise unusable for growth analysis. For valuable specimens of endangered species, however, each specimen is difficult to replace, thus the use of either otolith (e.g., if the preferred otolith is lost or damaged) is often valuable, when shown to be appropriate (Hobbs et al., 2007, 2019). If left and right otoliths exhibit systematic asymmetrical accretion patterns, however, this can greatly affect otolith-based

Peer] reviewing PDF | (2021:01:56842:2:0:NEW 10 Sep 2021) 
413 inferences when otolith side cannot be standardized. Here, we showed that age estimates from 414 paired left and right Delta Smelt otoliths were similar, with no evidence for differences in 415 accuracy or precision. These results suggest that reliable age and growth estimates can likely be 416 constructed from either left or right otoliths of Delta Smelt.

\section{Image Magnification}

418

419

420

421

422

423

424

425

426

427

428

429

430
During QAQC of image quality, older Delta Smelt specimens (e.g., $271 \mathrm{dph}$ ) often exhibited increment compaction toward the otolith edge, indicative of the ontogenetic reduction of growth rate in older fish. These rings were occasionally flagged as "low quality" by analysts due to their poor appearance when imaged at 200x magnification. Though these samples exhibited acceptable percent precision and accuracy $(\sim 95 \%)$, the increase in the raw daily error rate and consistent negative aging bias for these older individuals indicated that the finest daily rings were often missed by each analyst for these slow-growing specimens. By re-imaging the otoliths from the oldest $271 \mathrm{dph}$ fish at twice the magnification $(400 \mathrm{x})$ and re-analyzing the microstructures, the accuracy of age estimates increased significantly and exhibited no measurable bias. Though higher-resolution imaging requires additional time and computing power for capturing, storing, and processing larger datafiles, our results indicate that this additional effort significantly improved otolith-based age and growth estimates for older age classes of Delta Smelt.

\section{Cultured Versus Wild Fish}

The limitations of studying wild Delta Smelt include the species' sensitivity to handling and its rarity and protected status as a critically endangered species. The use of cultured fish was valuable for providing known-age specimens to verify the interpretation of otolith microstructures. The development and interpretation of otoliths in wild fish, however, could be more complex than for those in controlled laboratory studies (Campana, 2001). For example, environmental variability may influence otolith shape, increment appearance, or the timing of the first increment (Campana \& Casselman, 1993; Otterlei, 2002; Vignon \& Morat, 2010). Here, we demonstrated that otolith-somatic proportionality was similar among cultured and wild sub-adult Delta Smelt. Furthermore, standard back-calculation tools such as the Biological Intercept Model explicitly account for individual variation in otolith shape by proportionally adjusting growth estimates using individual-based somatic-otolith relationships (Campana, 1990). Nevertheless, further comparisons between cultured and wild fish could be valuable for assessing confidence in otolith-based inferences for the wild population. If possible, additional field-based studies using caged or marked-recaptured specimens could provide further insights regarding the interpretation of otoliths from wild Delta Smelt.

\section{CONCLUSIONS}

With Delta Smelt rapidly approaching extinction in the wild, it has become necessary to address increasingly complex questions for a wider variety of life stages with relatively few wild specimens. Otolith-based studies, once validated across all relevant life stages, can provide

Peer] reviewing PDF | (2021:01:56842:2:0:NEW 10 Sep 2021) 
453

454

455

456

457

458

459

460

461

462

463

464

465

466

467

468

469

470

471

472

473

474

475

476

477

478

479

480

481

482

483

484

485

486

487

488

489

490

491

492

493

494

495

496

valuable estimates of the size, age, growth, and phenology of individual fish to inform population models and directed conservation efforts. Here, we experimentally evaluated the accuracy and repeatability of otolith-based tools across multiple life stages of this critically endangered estuarine fish. Results indicated relatively high aging precision and accuracy, as well as similarity among cultured and wild individuals in otolith-somatic relationships. This study expands the validated otolith age range for Delta Smelt by $300 \%$ while providing an improved understanding of how key methodological factors are likely to affect confidence in otolith-based results. Such experimental assessments of the accuracy and repeatability of schlerochronological reconstructions remain key to their effective use in fisheries management and conservation.

\section{ACKNOWLEDGEMENTS}

We thank the many staff of the UC Davis Fish Conservation and Culture Laboratory for their assistance in rearing and archiving known-age Delta Smelt for this study. The UC Davis Department of Wildlife, Fish, and Conservation Biology (N. Fangue) and Center for Aquatic Biology and Aquaculture (L. Deanovic) provided laboratory space and logistical support. Constructive reviews from N. Bertrand and several anonymous reviewers greatly improved the manuscript. The views expressed herein are those of the authors and do not represent the official opinion of any employer, institution, or government agency.

\section{REFERENCES}

Abramoff MD, Magelhaes PJ, Ram SJ. 2006. Image Processing with ImageJ. In: Optical Imaging Techniques in Cell Biology. CRC Press, 249-258. DOI: 10.1201/9781420005615.ax4.

Black BA, Allman RJ, Schroeder ID, Schirripa MJ. 2011. Multidecadal otolith growth histories for red and gray snapper (Lutjanus spp.) in the northern Gulf of Mexico, USA: Multidecadal otolith growth histories for red and gray snapper. Fisheries Oceanography 20:347-356. DOI: 10.1111/j.1365-2419.2011.00588.x.

Black BA, Boehlert GW, Yoklavich MM. 2005. Using tree-ring crossdating techniques to validate annual growth increments in long-lived fishes. 62:9.

Buckmeier DL, Howells RG. Validation of Otoliths for Estimating Ages of Largemouth Bass to 16 Years. North American Journal of Fisheries Management 23:590-593. DOI: https://doi.org/10.1577/1548-8675(2003)023<0590:VOOFEA>2.0.CO;2.

Campana SE. 1990. How Reliable are Growth Back-Calculations Based on Otoliths? Canadian Journal of Fisheries and Aquatic Sciences 47:2219-2227. DOI: 10.1139/f90-246.

Campana SE. 1999. Chemistry and composition of fish otoliths: pathways, mechanisms and applications. Marine Ecological Progress Series 188:263-297.

Campana SE. 2001. Accuracy, precision and quality control in age determination, including a review of the use and abuse of age validation methods. Journal of Fish Biology 59:197242. DOI: 10.1006/jfbi.2001.1668.

Campana SE, Casselman JM. 1993. Stock Discrimination Using Otolith Shape Analysis. Canadian Journal of Fisheries and Aquatic Sciences 50:1062-1083. DOI: 10.1139/f93123.

Peer] reviewing PDF | (2021:01:56842:2:0:NEW 10 Sep 2021) 
Campana SE, Neilson JD. 1985. Microstructure of Fish Otoliths. Canadian Journal of Fisheries and Aquatic Sciences 42:1014-1032. DOI: 10.1139/f85-127.

Campana SE, Thorrold SR. 2001. Otoliths, increments, and elements: keys to a comprehensive understanding of fish populations? Canadian Journal of Fisheries and Aquatic Sciences 58. DOI: https://doi.org/10.1139/f00-177.

CDFG. 2010. State \& federally listed endangered \& threatened animals of California. California Department of Fish \& Game,State of California, The Natural Resources Agency, California. The Natural Rsources Agency, California.

Díaz-Gil C, Palmer M, Catalán IA, Alós J, Fuiman LA, García E, Gil M del M, Grau A, Kang A, Maneja RH, Mohan JA, Morro B, Schaffler JJ, Buttay L, Riera-Batle I, Tolosa B, Morales-Nin B. 2015. Otolith fluctuating asymmetry: a misconception of its biological relevance? ICES Journal of Marine Science 72:2079-2089. DOI: 10.1093/icesjms/fsv067.

Fey DP. 1999. Effects of preservation technique on the length of larval fish: Methods of correcting estimates and their implication for studying growth rates. Archive of Fishery and Marine Research 47:17-29.

Feyrer F, Nobriga ML, Sommer TR. 2007. Multidecadal trends for three declining fish species: Habitat patterns and mechanisms in the San Francisco Estuary, California, USA. Canadian Journal of Fisheries and Aquatic Sciences 64:723-734. DOI: 10.1139/F07048.

Feyrer F, Sommer T, Hobbs J. 2007. Living in a Dynamic Environment: Variability in Life History Traits of Age-0 Splittail in Tributaries of San Francisco Bay. Transactions of the American Fisheries Society 136:1393-1405. DOI: 10.1577/T06-253.1.

Fowler GM, Smith SJ. 1983. Length Changes in Silver Hake (Merluccius bilinearis) Larvae: Effects of Formalin, Ethanol, and Freezing. Canadian Journal of Fisheries and Aquatic Sciences 40:866-870.

Gillanders BM, Izzo C, Doubleday ZA, Ye Q. 2015. Partial migration: growth varies between resident and migratory fish. Biology Letters 11:20140850. DOI: 10.1098/rsbl.2014.0850.

Grimaldo LF, Sommer T, Van Ark N, Jones G, Holland E, Moyle PB, Herbold B, Smith P. 2009. Factors Affecting Fish Entrainment into Massive Water Diversions in a Tidal Freshwater Estuary: Can Fish Losses be Managed? North American Journal of Fisheries Management 29:1253-1270. DOI: 10.1577/m08-062.1.

Hammock BG, Moose SP, Solis SS, Goharian E, Teh SJ. 2019. Hydrodynamic Modeling Coupled with Long-term Field Data Provide Evidence for Suppression of Phytoplankton by Invasive Clams and Freshwater Exports in the San Francisco Estuary. Environmental Management 63:703-717. DOI: 10.1007/s00267-019-01159-6.

Hirose T, Kawaguchi K. 2001. Daily otolith increments and growth of reared chika Hypomesus japonicus larvae. Bulletin of the Japan Sea National Fisheries Research Institute:141144.

Hobbs JA, Bennett WA, Burton JE, Baskerville-Bridges B. 2007. Modification of the biological intercept model to account for ontogenetic effects in laboratory-reared delta smelt (Hypomesus transpacificus). Fishery Bulletin 105:30-38.

Hobbs JA, Lewis LS, Ikemiyagi N, Sommer T, Baxter RD. 2010. The use of otolith strontium isotopes ( $\mathrm{Sr}-87 / \mathrm{Sr}-86)$ to identify nursery habitat for a threatened estuarine fish. Environmental Biology of Fishes 89:557-569. DOI: 10.1007/s10641-010-9672-3. 
542

543

544

545

546

547

548

549

550

551

552

553

554

555

556

557

558

559

560

561

562

563

564

565

566

567

568

569

570

571

572

573

574

575

576

577

578

579

580

581

582

583

584

585
Hobbs JA, Lewis LS, Willmes M, Denney C, Bush E. 2019. Complex life histories discovered in a critically endangered fish. Scientific Reports 9:1-12. DOI: 10.1038/s41598-019-522738.

Hobbs JA, Moyle PB, Fangue N, Connon RE. 2017. Is Extinction Inevitable for Delta Smelt and Longfin Smelt? An Opinion and Recommendations for Recovery. San Francisco Estuary and Watershed Science 15:1-19. DOI: 10.15447/sfews.2017v15iss2art2.

Hoff GR, Logan DJ, Markle DF. 1997. Otolith Morphology and Increment Validation in Young Lost River and Shortnose Suckers. Transactions of the American Fisheries Society:8.

Hunter E, Laptikhovsky V, Hollyman P. 2018. Innovative use of sclerochronology in marine resource management. Marine Ecology Progress Series 598:155-158. DOI: 10.3354/meps 12664.

Lychakov DV, Rebane YT, Lombarte A, Demestre M, Fuiman LA. 2008. Saccular otolith mass asymmetry in adult flatfishes. Journal of Fish Biology 72:2579-2594. DOI: 10.1111/j.1095-8649.2008.01869.x.

Lychakov DV, Rebane YT, Lombarte A, Fuiman LA, Takabayashi A. 2006. Fish otolith asymmetry: Morphometry and modeling. Hearing Research 219:1-11. DOI: 10.1016/j.heares.2006.03.019.

Mager RC, Doroshov SI, Van Eenennaam JP, Brown R. 2004. Early Life Stages of Delta Smelt. In: Early Life History of Fishes in the San Francisco Estuary and Watershed. American Fisheries Society, 296.

Mahé K, Ider D, Massaro A, Hamed O, Jurado-Ruzafa A, Gonçalves P, Anastasopoulou A, Jadaud A, Mytilineou C, Elleboode R, Ramdane Z, Bacha M, Amara R, de Pontual H, Ernande B. 2019. Directional bilateral asymmetry in otolith morphology may affect fish stock discrimination based on otolith shape analysis. ICES Journal of Marine Science 76:232-243. DOI: 10.1093/icesjms/fsy163.

Martino JC, Fowler AJ, Doubleday ZA, Grammer GL, Gillanders BM. 2019. Using otolith chronologies to understand long-term trends and extrinsic drivers of growth in fisheries. Ecosphere 10. DOI: 10.1002/ecs2.2553.

Maunder MN, Punt AE. 2013. A review of integrated analysis in fisheries stock assessment. Fisheries Research 142:61-74. DOI: 10.1016/j.fishres.2012.07.025.

Meffe GK. 1986. Conservation Genetics and the Management of Endangered Fishes. :11.

Miller WJ, Manly BFJ, Murphy DD, Fullerton D, Ramey RR. 2012. An Investigation of Factors Affecting the Decline of Delta Smelt (Hypomesus transpacificus) in the Sacramento-San Joaquin Estuary. Reviews in Fisheries Science 20:1-19. DOI: 10.1080/10641262.2011.634930.

Miller SJ, Storck T. 1982. Daily Growth Rings in Otoliths of Young-of-the-Year Largemouth Bass. Transactions of the American Fisheries Society 111:527-530. DOI: 10.1577/15488659(1982) $111<527$.

Moksness E. 1992. Validation of daily increments in the otolith microstructure of Norwegian spring-spawning herring (Clupea harengus l.). ICES Journal of Marine Science 49:231235. DOI: 10.1093/icesjms/49.2.231.

Moyle PB, Brown LR, Durand JR, Hobbs JA. 2016. Delta smelt: Life history and decline of a once abundant species in the San Francisco Estuary. San Francisco Estuary and Watershed Science 14:1-30. DOI: 10.15447/sfews.2016v14iss2art6. 
586

587

588

589

590

591

592

593

594

595

596

597

598

599

600

601

602

603

604

605

606

607

608

609

610

611

612

613

614

615

616

617

618

619

620

621

622

623

624

625

626

627

628

629

630
Moyle PB, Herbold B, Stevens DE, Miller LW. 1992. Life History and Status of Delta Smelt in the Sacramento-San Joaquin Estuary, California. Transactions of the American Fisheries Society 121:67-77. DOI: 10.1577/1548-8659(1992)121<0067:LHASOD>2.3.CO;2.

Moyle PB, Hobbs JA, Durand JR. 2018. Delta Smelt and Water Politics in California. Fisheries 43:42-51. DOI: 10.1002/fsh.10014.

NatureServe. 2014. Hypomesus transpacificus. The IUCN Red List of Threatened Species 2014. DOI: https://dx.doi.org/10.2305/IUCN.UK.2014-3.RLTS.T10722A174778740.en.

Ohama H. 1990. Age determination of Japanese smelt with daily otolith increment. Nippon Suisan Gakkaishi 56:1053-1057.

Otterlei E. 2002. Temperature dependent otolith growth of larval and early juvenile Atlantic cod (Gadus morhua). ICES Journal of Marine Science 59:851-860. DOI: 10.1006/jmsc.2001.1300.

Pannella G. 1971. Fish Otoliths: Daily Growth Layers and Periodical Patterns. Science 173:1124. DOI: $10.1126 /$ science.173.4002.1124.

R Core Team. 2019. R: A language and environment for statistical computing.

Roberts ME, Wetzel JE, Brooks RC, Garvey JE. 2004. Daily Increment Formation in Otoliths of the Redspotted Sunfish. North American Journal of Fisheries Management 24:270-274. DOI: $10.1577 / \mathrm{m} 02-197$.

Rogers TA, Fowler AJ, Steer MA, Gillanders BM. 2019. Resolving the early life history of King George whiting (Sillaginodes punctatus: Perciformes) using otolith microstructure and trace element chemistry. Marine and Freshwater Research 70:1659. DOI: 10.1071/MF18280.

Runge MC. 2011. An Introduction to Adaptive Management for Threatened and Endangered Species. Journal of Fish and Wildlife Management 2:220-233. DOI: 10.3996/082011JFWM-045.

Sakaris PC, Buckmeier DL, Smith NG. 2014. Validation of Daily Ring Deposition in the Otoliths of Age-0 Alligator Gar. North American Journal of Fisheries Management 34:1140-1144. DOI: 10.1080/02755947.2014.951806.

Sakaris P, Irwin E. 2008. Validation of daily ring deposition in the otoliths of age-0 channel catfish. North American Journal of Fisheries Management 28:212-218. DOI: 10.1577/M06-176.1.

Sepulveda A. 1994. Daily growth increments in the otoliths of European smelt Osmerus eperlanus larvae. Marine Ecology Progress Series 108:33-42. DOI: 10.3354/meps 108033 .

Smith WE, Newman KB, Mitchell L. 2020. A Bayesian hierarchical model of postlarval delta smelt entrainment: integrating transport, length composition, and sampling efficiency in estimates of loss. Canadian Journal of Fisheries and Aquatic Sciences 77:789-813. DOI: 10.1139/cjfas-2019-0148.

Sommer T, Armor C, Baxter R, Breuer R, Brown L, Chotkowski M, Culberson S, Feyrer F, Gingras M, Herbold B, Kimmerer W, Mueller-Solger A, Nobriga M, Souza K. 2007. The collapse of pelagic fishes in the Upper San Francisco Estuary. Fisheries 32:270-277. DOI: 10.1577/1548-8446(2007)32[270:TCOPFI]2.0.CO;2.

Sommer T, Mejia F, Nobriga ML, Feyrer F, Grimaldo LF. 2011. The Spawning Migration of Delta Smelt in the Upper San Francisco Estuary. San Francisco Estuary and Watershed Science 9:1-16.

Peer) reviewing PDF | (2021:01:56842:2:0:NEW 10 Sep 2021) 
631 Starrs D, Ebner BC, Fulton CJ. 2016. All in the ears: Unlocking the early life history biology and spatial ecology of fishes. Biological Reviews 91:86-105. DOI: 10.1111/brv.12162.

Stevenson DK, Campana SE. 1992. Otolith Microstructure Examination and Analysis. Ottawa, Canada: Department of Fisheries and Ocean.

Tjørve KMC, Tjørve E. 2017. The use of Gompertz models in growth analyses, and new Gompertz-model approach: An addition to the Unified-Richards family. PLOS ONE 12:e0178691. DOI: 10.1371/journal.pone.0178691.

Trofimova T, Alexandroff SJ, Mette MJ, Tray E, Butler PG, Campana SE, Harper EM, Johnson ALA, Morrongiello JR, Peharda M, Schöne BR, Andersson C, Andrus CFT, Black BA, Burchell M, Carroll ML, DeLong KL, Gillanders BM, Grønkjær P, Killam D, Prendergast AL, Reynolds DJ, Scourse JD, Shirai K, Thébault J, Trueman C, de Winter N. 2020. Fundamental questions and applications of sclerochronology: Communitydefined research priorities. Estuarine, Coastal and Shelf Science 245:106977. DOI: 10.1016/j.ecss.2020.106977.

U.S. Fish and Wildlife Service. 1993. Determination of Threatened Status for the Delta Smelt. Federal Register 58:12854-12864. DOI: http://ecos.fws.gov/docs/federal_register/fr2751.pdf.

Vignon M, Morat F. 2010. Environmental and genetic determinant of otolith shape revealed by a non-indigenous tropical fish. Marine Ecology Progress Series 411:231-241.

Wang J. 2007. Spawning, Early Life Stages, and Early Life Histories of the Osmerids Found in the Sacramento-San Joaquin Delta of California. US Bureau of Reclamation 38:110.

Willmes M, Hobbs JA, Sturrock AM, Bess Z, Lewis LS, Glessner JJG, Johnson RC, Kurth R, Kindopp J. 2018. Fishery collapse, recovery, and the cryptic decline of wild salmon on a major California river. Canadian Journal of Fisheries and Aquatic Sciences 75:1836-

656 1848. DOI: 10.1139/cjfas-2017-0273. 


\section{Figure 1}

Morphological features of Delta Smelt and their otoliths.

(A) Larval (left) and adult (right) Delta Smelt and associated length measurements: standard length (SL), total length ( $\mathrm{TL}$ ), fork length (FL, adult only). (B) Ontogenetic development and morphology of sagittal otoliths from individuals of ages 30 to 271 days-post-hatch (dph). Dorsal-ventral (DV) and rostral-postrostral (RP) dimensions, and the dorsal aging trajectory (black/white line) are shown for the $180 \mathrm{dph}$ otolith. (C) A polished sagittal section of the dorsal lobe of a Delta Smelt otolith exhibiting 180 daily rings from the outer edge of the core to the outer edge of the otolith (death). Tick marks in (C) represent 30-day intervals along the aging trajectory. Delta Smelt artwork by Adi Khen. 

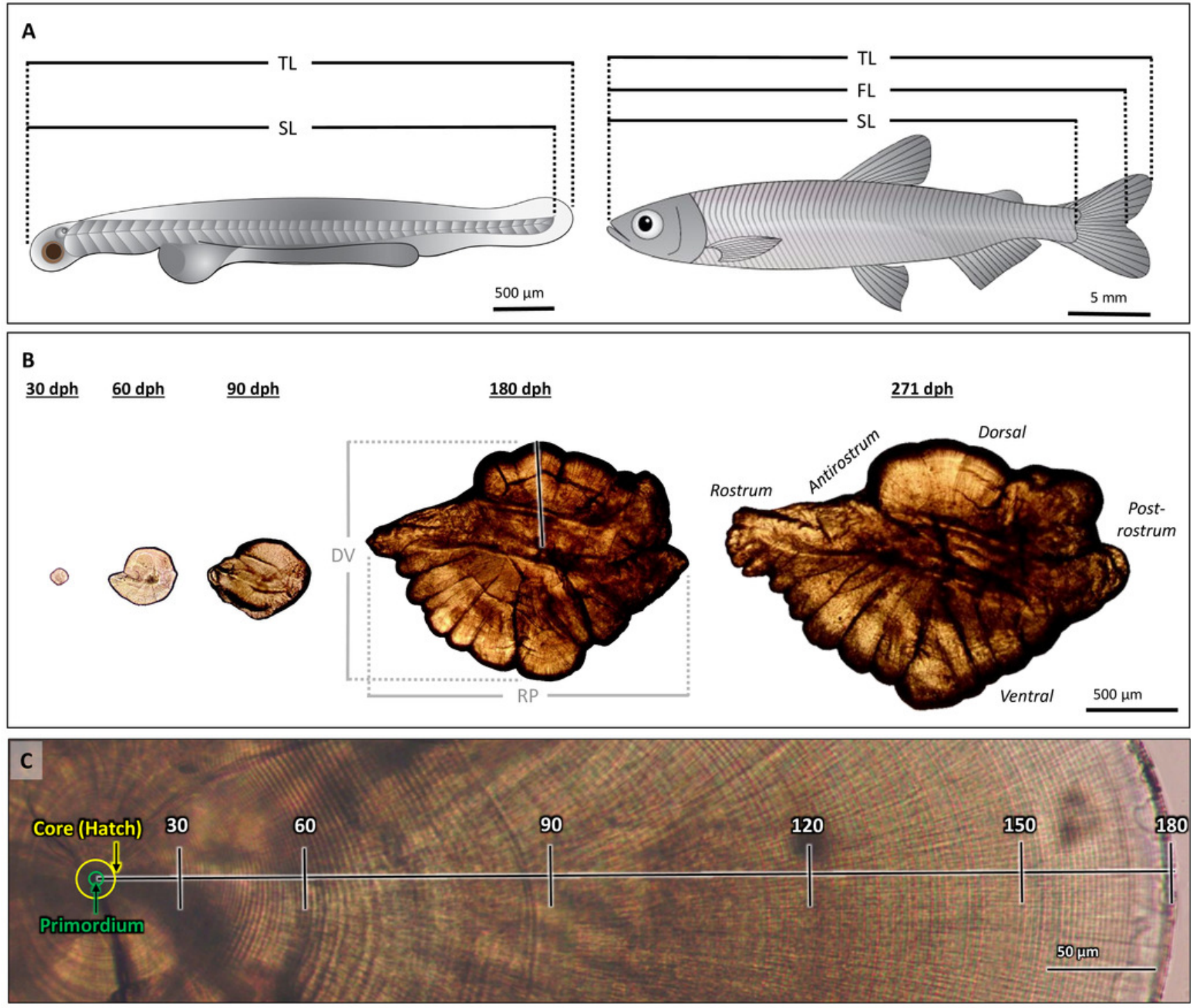


\section{Figure 2}

Otolith and Somatic Growth in Delta Smelt.

(A) Standard length versus age and fitted Gompertz growth curve, (B) otolith size (radius) versus standard length and fitted linear model, (C) density plot of otolith core sizes, and (D) otolith growth trajectories with known ages (vertical dashed lines) examined in the present study. In panel (B), "X" symbols represent wild Delta Smelt captured in 2019 and the inset boxplot shows the otolith-somatic size relationship for wild and cultured fish $>35 \mathrm{~mm}$. 

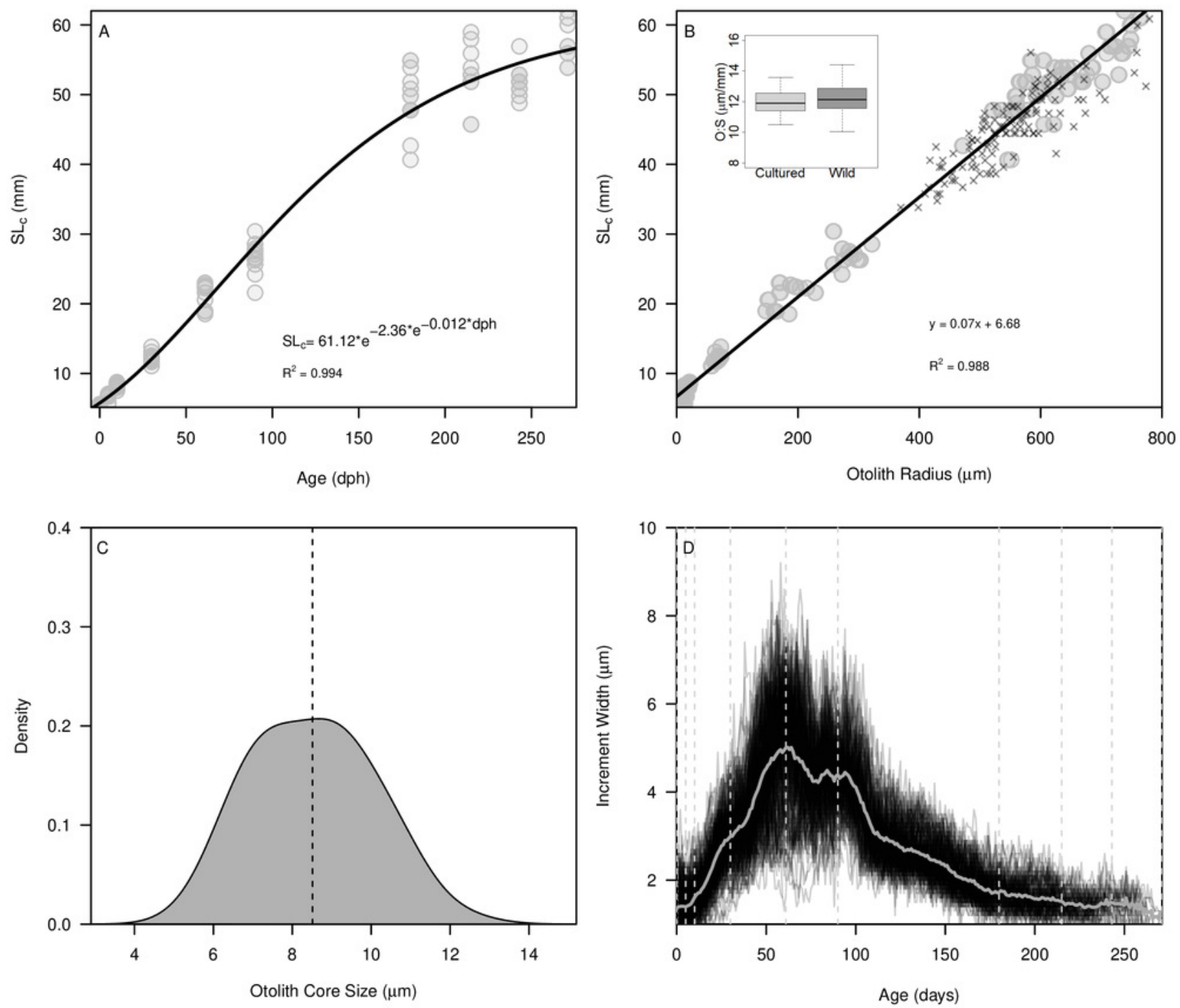
Figure 3

Aging accuracy versus fish age.

Mean \pm SD error $(A)$ and percent error $(B)$ in the accuracy of age estimates for Delta Smelt are plotted in relation to the known age for each group. 

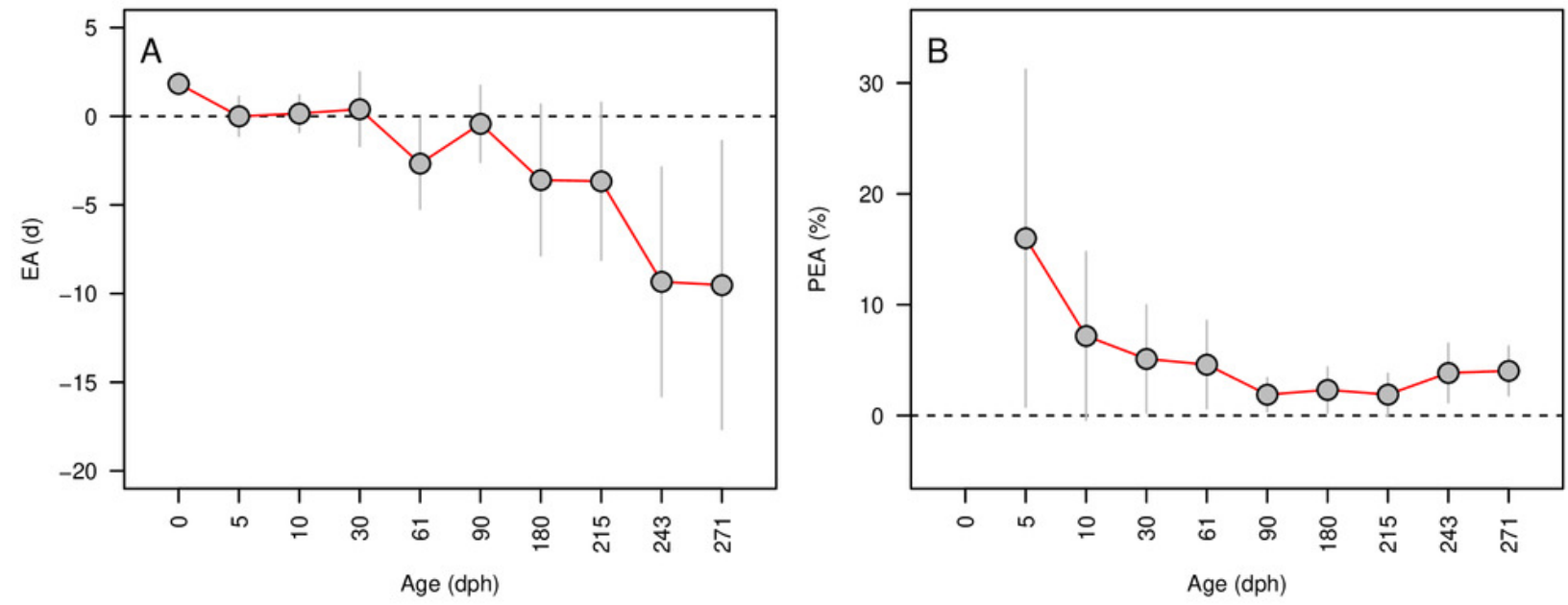


\section{Figure 4}

Aging accuracy and precision among analysts.

(A) Raw error in accuracy (EA in dph), (B) absolute percent error in accuracy (PEA, \%), (C)

raw error in precision (EP in dph), (D) absolute percent error in precision (PEP, \%). Points and bars represent the mean error value for each analyst; segments represent $1 \mathrm{~s}$.d. The global mean for all analysts is shown by the red dashed line. Only specimens $\geq 10 \mathrm{dph}$ were included in the analysis. Statistical results in Table 2. 

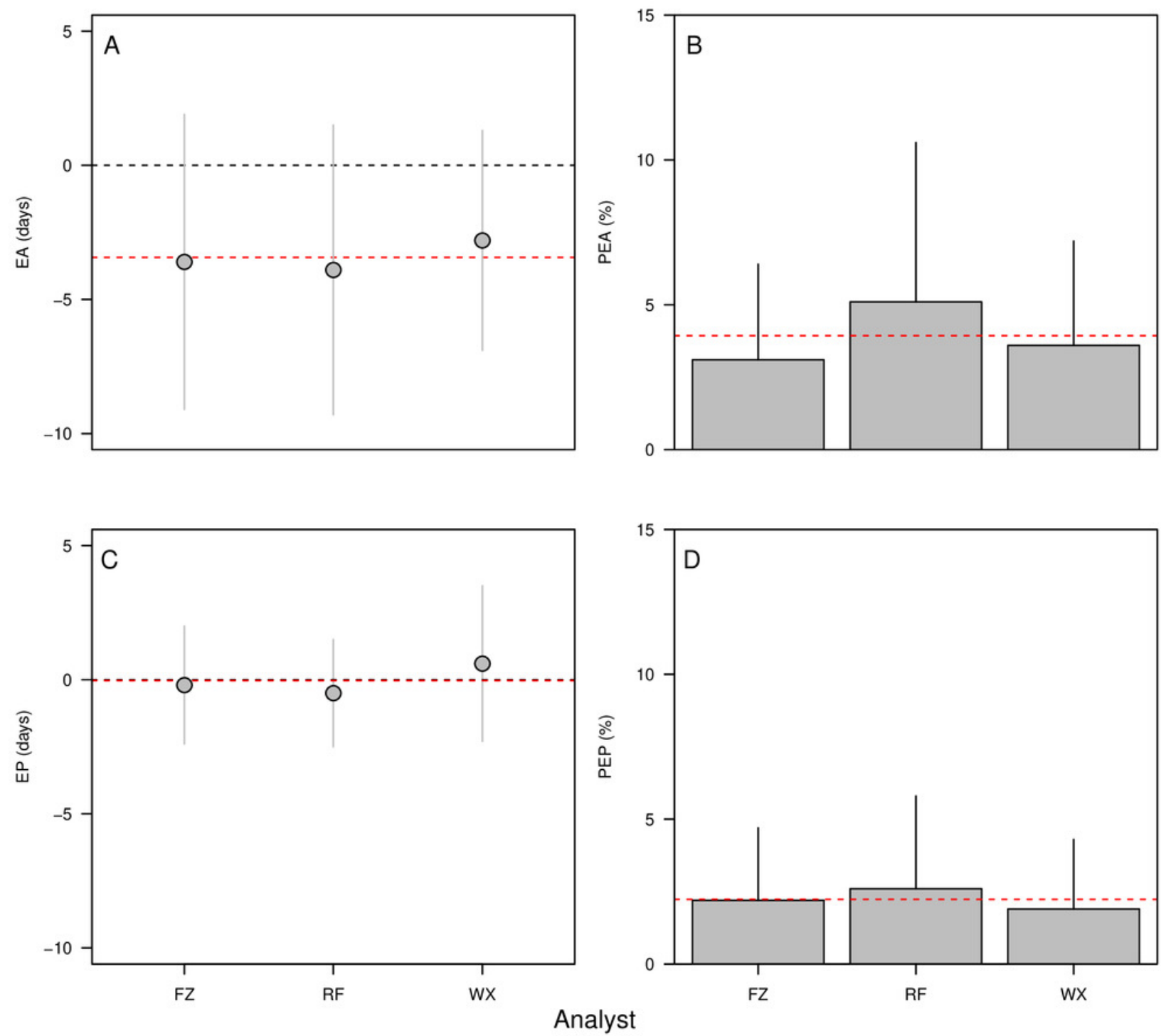


\section{Figure 5}

Variation in aging accuracy in relation to otolith side and image magnification.

Raw error (EA, dph) among left versus right otoliths (A) and 200x versus 400x images (B). Absolute percent error (PEA, \%) among left versus right otoliths (C) and 200x versus 400x images (D). Comparisons between left and right otoliths included fish ages 90 and $180 \mathrm{dph}$, whereas comparisons among magnifications focused on the slowest-growing 271-dph age class. Statistical results in Table 3. 

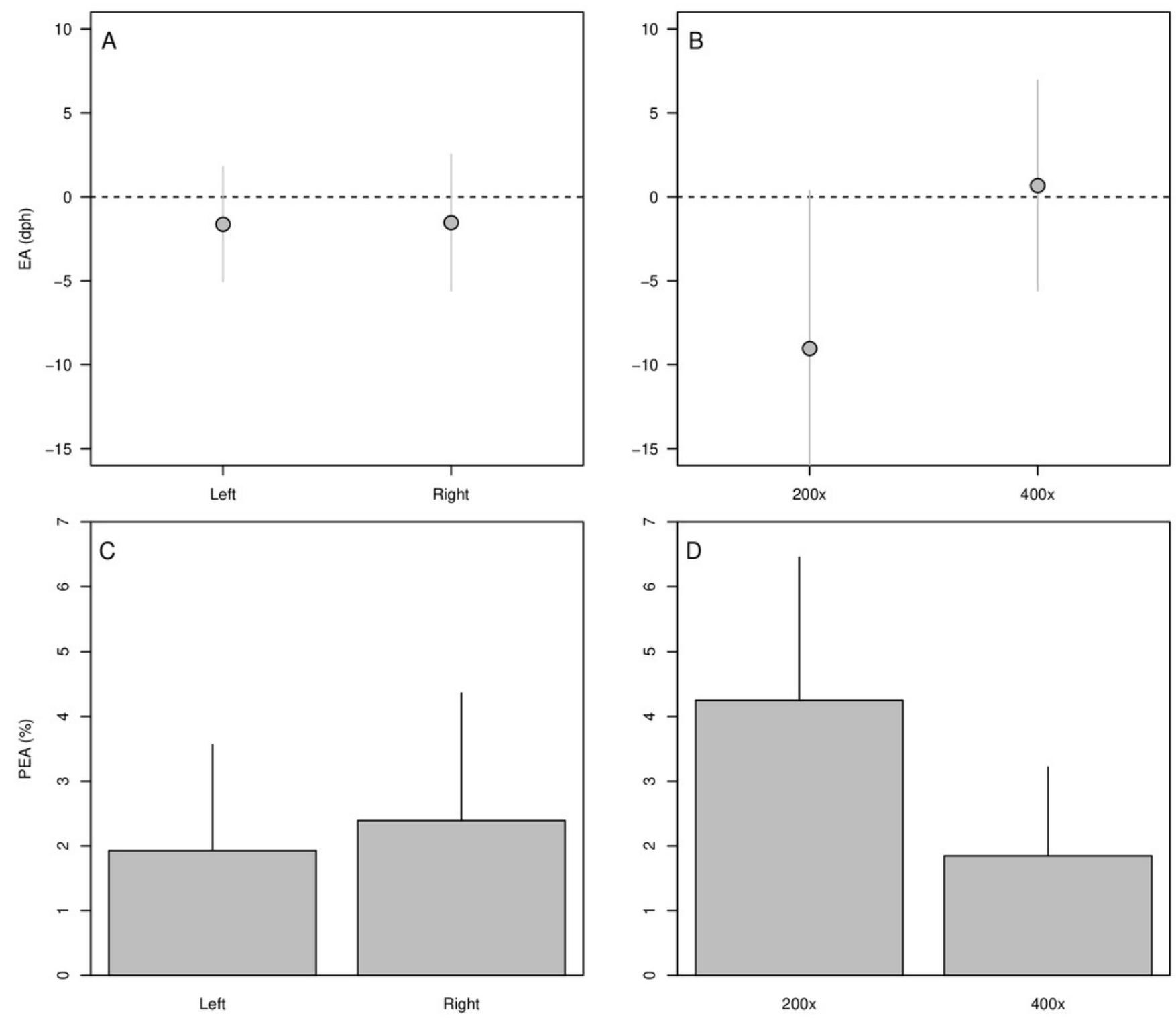


\section{Table $\mathbf{1}$ (on next page)}

Samples used in the present study.

Sample size $(\mathrm{N})$ is shown by age class, along with the mean standard length for the subsample from each age class. The number of specimens for which paired left and right otoliths were used to examine symmetry (Sym) and paired images at 200x and 400x magnification to examine magnification (Mag) are also provided. 


\begin{tabular}{ccccc}
\hline Age $(\mathrm{dph})$ & $\mathrm{N}$ (fish) & $\mathrm{SL}_{\mathrm{c}}(\mathrm{mm})$ & Sym & Mag \\
\hline 0 & 10 & $5.41 \pm 0.16$ & & \\
5 & 10 & $6.63 \pm 0.49$ & & \\
10 & 13 & $8.25 \pm 0.33$ & & \\
30 & 10 & $12.27 \pm 0.74$ & & \\
61 & 10 & $20.79 \pm 1.75$ & & \\
90 & 11 & $26.55 \pm 2.22$ & 5 & \\
180 & 14 & $49.15 \pm 4.04$ & 5 & \\
215 & 10 & $52.75 \pm 4.28$ & & \\
243 & 11 & $51.93 \pm 2.04$ & & \\
271 & 9 & $57.38 \pm 2.86$ & & 9 \\
\hline
\end{tabular}

1 


\section{Table 2 (on next page)}

Effects of observer, otolith side, and life stage on aging accuracy.

Results of a linear model examining the effects of observer (obs), otolith side (left vs. right), and fish age group (90 vs $180 \mathrm{dph}$ ) on the absolute percent error in accuracy (PEA) of age estimates. Factors include: obs-analyst, oto-otolith side, known-known age. DF-degrees of freedom, SS-sum-of-squares, MS-mean squares. No significant effects were detected (P > 0.05). 


\begin{tabular}{llllll}
\hline Factor & df & SumSq & MeanSq & F & P \\
\hline obs & 2 & 4.39 & 2.1965 & 0.3039 & 0.7393 \\
oto & 1 & 0.01 & 0.0051 & 0.0007 & 0.9788 \\
known & 1 & 0.13 & 0.1286 & 0.0178 & 0.8944 \\
obs:oto & 2 & 20.87 & 10.4372 & 1.4441 & 0.2460 \\
obs:known & 2 & 12.17 & 6.0854 & 0.8420 & 0.4371 \\
oto:known & 1 & 1.16 & 1.1574 & 0.1601 & 0.6908 \\
obs:oto:known & 2 & 6.51 & 3.2562 & 0.4505 & 0.6400 \\
\hline Residuals & 48 & & & &
\end{tabular}

1 


\section{Table 3 (on next page)}

Effects of observer and image magnification on aging accuracy.

Statistical results of the linear model examining the additive and interactive effects of observer (obs) and image magnification (mag: 200x vs 400x) on the absolute percent error in accuracy (PEA) of age estimates for the slowest-growing $271 \mathrm{dph}$ age group. Significant Pvalues are in bold. DF-degrees of freedom, SS-sum-of-squares, MS-mean squares. 


\begin{tabular}{llllll}
\hline Factor & DF & SS & MS & F & P \\
\hline obs & 2 & 213.645 & 106.823 & 20.5102 & $<\mathbf{0 . 0 0 1}$ \\
mag & 1 & 192.175 & 192.175 & 36.8980 & $<\mathbf{0 . 0 0 1}$ \\
obs:mag & 2 & 8.592 & 4.296 & 0.8248 & 0.4438 \\
\hline Residuals & 54 & 281.246 & 5.208 & &
\end{tabular}

1 